\title{
O currículo de licenciatura em educação física e a fabricação do sujeito-cliente
}

\author{
MÁRIO LUIZ FERRARI NUNES \\ Universidade Estadual de Campinas, São Paulo, SP, Brasil
}

MARCOS GARCIA NEIRA

Universidade de São Paulo, São Paulo, SP, Brasil

RESUMO

São apresentados os resultados de uma etnografia que objetivou compreender como o currículo de licenciatura em educação física (EF) de uma instituição de ensino superior privada (IESp) promove modos de subjetivação, a fim de produzir a identidade do futuro professor em tempos de lutas por mudanças sociais e por imposições neoliberais de modos de ser produtivos e eficientes. Os estudos culturais na sua perspectiva pós-estruturalista foram adotados como aporte teórico e a arquegenealogia foucaultiana inspirou a forma de análise de documentos e práticas. Dentre os sujeitos projetados pelo currículo em xeque, o esforço recaiu na análise da produção do sujeito-cliente, tomando por referência a noção de governamentalidade compreendida como a arte de governo de si e dos outros. Enquanto objeto e objetivo do ensino superior (ES) privado, a produção do sujeito-cliente exige a reformulação contínua do currículo e naturaliza estratégias de regulação que visam à submissão total da vida às regras do mercado.

PALAVRAS-CHAVE

currículo; formação inicial em educação física; ensino superior. 


\title{
CURRICULUM FOR THE PHYSICAL EDUCATION TEACHING DEGREE AND THE MANUFACTURING OF A SUBJECT-CLIENT
}

\begin{abstract}
Results from an ethnographical study aimed to understand how a physical education undergraduate curriculum at a private college institution promotes modes of subjectivation in order to produce identities of future teachers in times of struggle for social changes, and in the context of neoliberal impositions of being productive and efficient. Cultural studies from a poststructuralist perspective were adopted as a theoretical basis and Foucauldian archegenealogy grounded the analysis of documents and practices. Among the individuals affected by the curriculum in question, analyses continually fell on the production of the subject-client, using the notion of governmentality - understood as the art of governing oneself and others - as reference. As private colleges have certain objectives, the production of a subject-client requires the continuous reformulation of curricula and naturalizes regulatory strategies that aim at submitting every aspect of life to the rules of the market.
\end{abstract}

KEYWORDS

curriculum; initial formation in physical education; higher education.

\section{EL CURRÍCULO DE FORMACIÓN EN EDUCACIÓN FÍSICA Y LA FABRICACIÓN DEL SUJETO-CLIENTE}

\section{RESUMEN}

Se presentan los resultados de una etnografía que tuvo como objetivo comprender cómo el currículo de licenciatura en educación física de una Institución de Enseñanza Superior promueve modos de subjetivación para producir la identidad del futuro maestro en tiempos de luchas por cambios sociales e imposiciones neoliberales en formas de ser productivo y eficiente. Los estudios culturales en su perspectiva postestructuralista fueron adoptados como una contribución teórica y la arqueogenealogía foucaultiana inspiró el análisis de documentos y prácticas. Entre los individuos proyectados por el currículo en cuestión, el esfuerzo se centró en el análisis de la producción del sujeto-cliente, tomando como referencia la noción de gubernamentalidad entendida como el arte de gobernarse a sí mismo y a los demás. Como objeto y objetivo de la universidad privada, la producción del sujeto-cliente requiere la continua reformulación del currículo y naturaliza las estrategias reguladoras que apuntan a la sumisión total de la vida a las reglas del mercado.

PALABRAS CLAVE

currículo; la formación inicial en educación física; educación superior. 


\section{INTRODUÇÃO}

O sujeito-cliente, termo cunhado por Veiga-Neto (2000), é uma construção das políticas culturais atuais que regulam a conduta da vida pública e privada. Ele entra em jogo, substituindo a concepção de sujeito essencializado, centrado, estável e protegido sob o guarda-chuva do Estado-nação, que anteriormente lhe dava guarida e uma sensação fixa de pertencimento. $\mathrm{O}$ sujeito-cliente está no jogo cambiante da globalização, solapando a noção de que existe uma identidade nacional capaz de unificar seus membros. Se, outrora, a identidade nacional fazia obscurecer as diferenças de gênero, classe, raça etc., diante da globalização esse aspecto ganha outros contornos e fins. O sujeito-cliente é um ser cosmopolita, descentrado e fragmentado.

Essa identidade do sujeito é mais um efeito das mudanças paradigmáticas que transformaram a retórica do capitalismo da produção para a do consumo, condicionada pelo deslocamento da responsabilidade da organização da vida pública do Estado para o mercado (Ball, 2004). A identidade fornecida pelo Estado-nação era custosa e conflituosa, em função dos gastos com a vigilância, o disciplinamento, a organização e a regulação do corpo do trabalhador. Já a administração da identidade do sujeito-cliente é de sua inteira responsabilidade por meio de discursos do tipo: "faça você mesmo". Afinal, o mercado, ao contrário do Estado, não quer dispender recursos com seus sujeitos, mas sim ganhar com eles. Nesse caso, não há especificidade acerca de quem são. A sociedade do consumo não está preocupada com as questões de gênero, classe, raça etc. Nela, essas políticas de identidade se apagam. O que importa são sujeitos capazes de consumir.

Para que sua ação social se efetive, o sujeito-cliente vivencia a concepção de liberdade individual. Trata-se de uma tática/técnica vital para a forma de governo do Estado e dos sujeitos produzida pelo neoliberalismo (Veiga-Neto, 2000). O ponto central é a crença em que cada um é levado a pensar que é livre para fazer suas escolhas, gerando uma sobrevalorização do individualismo. A questão passa a ser, portanto, como esse sujeito é fabricado e regulado.

Se não bastasse dizer que a competição é uma característica dos viventes, propaga-se que o ser humano é possuidor de uma capacidade inerente de fazer opções. O discurso do livre-arbítrio incorporou-se aos discursos do mercado. Oferecem-se infinitas possibilidades de aquisição, participação e consumo. É por aqui que o sujeito se identifica com os objetos produzidos pela atividade econômica, quer seja produto, mensagem ou serviço. Por aqui, o corpo, as práticas corporais, a convivência entre as pessoas, a educação, o ensino superior (ES), a educação física (EF) etc. ganham novos significados. Para decidir o que pensa ser melhor ou mais conveniente para si, o sujeito-cliente torna-se alvo de uma infinita gama de estímulos, sugestões, apelos e seduções (Veiga-Neto, 2000). O problema não para por aí, pois as interpelações que o atingem e os cenários em que atua mudam a todo o instante. É aqui que o currículo entra em cena.

A noção de currículo ora empregada ultrapassa a definição hegemônica de texto prescritivo de conteúdos, métodos e/ou avaliações escolares ou de seleção de conhecimentos produzidos pela humanidade a serem ensinados. É aqui entendido como um espaço-tempo que envolve relações de poder, tenciona prevalecer 
certa concepção de sujeito e sociedade e potencializa a produção de identidades. Assim sendo, o currículo é um campo de negociação entre as diferentes culturas que convivem na escola, ressignificando experiências (Lopes e Macedo, 2011).

Popkewitz (1994) explana que o currículo se baseia em um determinado sistema de pensamento que ordena e classifica informações, conceitos, regras e padrões. Cada sistema de pensamento é uma forma de perceber e responder ao mundo, bem como a si mesmo. Essas regras e padrões produzem tecnologias sociais que nada mais são que "o conjunto de métodos e estratégias que guiam e legitimam o que é razoável/não razoável como pensamento, ação, autorreflexão" (p. 193). São exemplos de tecnologia social presentes no currículo o modo de organizar o ensino pelo planejamento, definição de métodos, seleção de materiais didáticos, os casos apresentados em sala de aula, as atividades realizadas, a forma de avaliação e seus propósitos, assim como os conteúdos dos comunicados, as regras e normas institucionais, as políticas de contratação de profissionais da educação, dispensa e gestão, a organização e distribuição do tempo e dos espaços, bem como os seus usos.

A tecnologia social promove discursos e valores que tanto codificam determinadas maneiras de agir, ver e falar como constroem certas formas de razão e individualidade. Enfim, produzem dispositivos de governamentalidade (Foucault, 2005), isto é, estratégias e práticas que, em conexões com as relações de poder, visam a governar tanto os sujeitos do currículo (seu alvo) como permitir aos sujeitos se autogovernarem. Em outras palavras, fabricar as identidades destes tempos, pois, como afirma Larrosa (1994)

(...) a própria experiência de si não é senão o resultado de um complexo processo histórico de fabricação, no qual se entrecruzam os discursos que definem a verdade do sujeito, as práticas que regulam seu comportamento e as formas de subjetividade nas quais se constitui sua própria interioridade. É a própria experiência de si que se constitui historicamente como aquilo que pode e deve ser pensado. (p. 43)

São esses aspectos que tornam necessário historicizar o currículo da licenciatura em EF de uma instituição de ensino superior privada (IESp) e o modo como suas tecnologias sociais operam subjetividades.

\section{A PESQUISA}

A pesquisa ocorreu no interior de um centro universitário com fins lucrativos. Realizou-se etnografia reconceptualizada pelos estudos culturais a partir de pressupostos pós-estruturalistas (Frow e Morris, 2006), tendo a arquegenealogia foucaultiana como ferramenta de análise. A arquegenealogia permite o entendimento da IESp como dispositivo, uma vez que configura uma rede de relações que envolvem práticas discursivas e não discursivas enquanto produção da cultura, logo, das relações de poder, que tanto requerem condições complexas de existência como governam a experiência vivida pelos sujeitos. A etnografia possibilita a investigação dos efeitos dessas relações, situando a produção dos discursos e das práticas 
institucionais em meio a jogos de força e estratégias construídas em circunstâncias singulares e localizadas.

Os dados foram produzidos no transcorrer de dois anos em tempos e espaços diferenciados. As observações ocorreram no âmbito da sala de aula de um curso de EF que forma licenciados e bacharéis, bem como nas práticas do cotidiano institucional. O material empírico constituiu-se por observações sistemáticas registradas em diário de campo, descrição do espaço aberto de circulação dos sujeitos e coleta de informações provenientes de e-mails institucionais, material publicitário, portal da internet, instrumentos e regulamentos de avaliação e documentos referentes ao curso de EF.

\section{A OPERAÇÃO CURRÍCULO E O SUJEITO-CLIENTE}

O sujeito-cliente alvo do centro universitário que acolheu a investigação são os representantes das classes sociais $\mathrm{C}, \mathrm{D}$ e $\mathrm{E}$, justamente os que compõem a maior demanda por vagas no ES. Mediante a ampla concorrência entre as IESp em busca desse sujeito-cliente, a entidade atua de forma ímpar. A estratégia central para captar alunos de uma classe social específica está na oferta de cursos em horários alternativos e com preços variados. Com isso, espera-se atingir uma população que não disponibiliza de muitos recursos financeiros e dos horários comuns para realizar o sonho de obter um diploma. Além dos tradicionais cursos matutino e noturno, são ofertadas, com valores promocionais, aulas no período vespertino e em cursos denominados localmente como turno da madrugada: das $05 \mathrm{~h} 45$ às $08 \mathrm{~h} 40$ e das $23 \mathrm{~h} 00$ à $01 \mathrm{~h} 45$. Nesses horários também ocorrem oito cursos de pós-graduação lato sensu cujo valor médio da mensalidade é inferior ao praticado pela concorrência. O turno das $05 \mathrm{~h} 45$ é o que mais cresce em quantidade de matrículas, explicitando as necessidades desses sujeitos estudantes para concatenar o exercício profissional e o estudo, pois, considerando o público alcançado, o primeiro torna-se requisito para a manutenção do segundo ${ }^{1}$.

No caso específico da licenciatura em EF, as aulas ocorrem nos períodos matutino, vespertino e noturno, cujas taxas são específicas. Esse contexto propicia o acesso de uma população plural no que respeita à faixa etária, à classe social, ao local de moradia, às condições de transporte, aos horários da jornada de trabalho, entre tantas características.

É interessante ressaltar que, em função da variedade de horários, os estudantes transitam entre os turnos. Alguns cursam duas faculdades concomitantemente. Outros, conforme muda o seu vínculo laboral, transferem o período de estudo. A constante movimentação é facilitada pelo fato de que as disciplinas, em geral, são ministradas pelo mesmo docente ou, em caso contrário, há a orientação dos gestores para que os conteúdos transmitidos e as avaliações sejam idênticos. Mesmo sem ser oficial, essa flexibilização permite ao aluno repor as aulas que porventura tenha faltado.

1 Fontes: diário de campo, portal da internet e material publicitário. 
Como tecnologia do currículo, os horários e os valores alternativos das mensalidades ensinam não apenas formas de articulação entre o estudo e o trabalho, mas também o sentido da importância de criação de estratégias diferenciadas para seduzir clientes e a manutenção da empresa diante das "forças do mercado". O que se aprende/reforça é que o capitalismo de livre mercado exige, constantemente, novas fórmulas para a competitividade e, para tal, tanto a vida das pessoas como o tempo devem ser redimensionados. Visando à sobrevivência e ao alcance dos seus objetivos, o sujeito-cliente incorpora uma das exigências atuais do mundo do trabalho: a flexibilidade.

Tantas possibilidades de acesso ao ES favorecem a existência de uma sociedade formada por sujeitos que são objetos e parceiros do governo (Veiga-Neto, 2000). Cada qual é, ao mesmo tempo, alvo dessa aprendizagem e autogoverna sua atuação produtiva, pois, além de vivenciá-la e atuar nesses moldes, terá tudo para colocar em circulação essas formas de pensar: a competitividade e a produtividade dos elementos com que venha a trabalhar. Poderá ser mais um a buscar fórmulas criativas de concorrência. Diante das metas a serem alcançadas pelo país e, individualmente, por cada sujeito, tanto o valor das mensalidades quanto os horários disponibilizados corroboram a consolidação das transformações econômicas, políticas e culturais fomentadas pelo neoliberalismo.

A nova cultura do ES, sem dúvida, modifica a vida dos envolvidos. A biblioteca da instituição permanece fechada apenas entre 01h00 e 05h00 da manhã. Em posse desses dados, pode-se indagar: como estão organizadas as demais atividades daqueles que atuam nesses períodos? Não há como negar que os sujeitos, diante das necessidades de adequação dos horários de trabalho com os de estudo, elaboraram outras formas de comportamento quanto às horas de sono, alimentação, transporte, lazer, estudo, relações amorosas, parentais e comunitárias, entre tantas. Suas vidas são reguladas por essa possibilidade de acesso e frequência ao ES.

Numa cascata de efeitos, a vida da localidade também se altera. A movimentação de pessoas em horários incomuns pode fomentar a necessidade de novas políticas de transporte e segurança pública e, assim, incentivar outros setores de serviço a colocar em ação novos exércitos de mão de obra. Não à toa, explica Foucault (2008), no neoliberalismo a grade de inteligibilidades econômica se espraia por todos os setores da sociedade, fazendo com que o sujeito tenha um comportamento econômico. Basta verificar que no entorno da instituição floresceu uma quantidade surpreendente de ambulantes que comercializam alimentos, ali permanecendo por longos períodos. Com base em Hall (1997), podemos afirmar que essas mudanças transformam rapidamente o social, gerando intensos deslocamentos culturais e, consequentemente, produzindo novas identidades.

As ofertas diversificadas relacionam-se com estratégias de marketing que visam garantir, de um lado, a manutenção financeira e a expansão da instituição (matrículas e espaço físico) e, de outro, o cumprimento da sua missão educativa. Os discursos dos gestores enfatizam, além do aspecto da concorrência, a importância de alcançar uma população que encontra dificuldades para realizar sua formação em função dos custos e dos horários de trabalho, afirmando seu legado 
histórico no campo educacional ${ }^{2}$. Esses fluxos culturais são recheados de intenções globais e particulares que negociam as tensões entre as partes envolvidas. O efeito dessa negociação se articula em novas formas de significações para o ES e para a própria instituição.

A grande procura pelos horários alternativos das aulas e pelas condições de pagamento indica a força das reformas estruturais atuais. Mais do que simples oportunidade de acesso aos conhecimentos para uma população outrora alijada do ambiente universitário, tantas ofertas materializam de vez os discursos das instituições supranacionais acerca da condicionalidade destes tempos. Nas imposições do Banco Mundial, o acesso ao ES passa a ser a via preferencial para a redução da pobreza do país, ao representar a oportunidade de atingir a qualificação exigida por uma economia de mercado globalizada para os sujeitos das classes sociais ascendentes (Barreto e Leher, 2008).

Se para muitos estudantes essas condições podem suprimir possíveis situações de abandono de estudos, para a instituição essa disponibilidade aos interessados significa reserva de mercado. Afinal, oferece serviços diferenciados e ganha terreno na competição entre as IESps, outra característica emergente das reformas educacionais deflagrada por órgãos como a Organização Mundial do Comércio (OMC) e a Organização para a Cooperação e Desenvolvimento Econômico (OCDE). Mediante as análises de Bauman (1999), é possível afirmar que existe um consenso sobre a necessidade de investimento para que a diversidade prospere, acarretando nos benefícios ao mercado.

Como fruto da ênfase atual em políticas de inclusão, o sujeito-cliente se insere nessa lógica a partir dos discursos que lhe avisam que, na ausência de uma formação superior, estará fadado a compor o grupo dos que amargam dificuldades socioeconômicas. Para Hall (2003, p. 77), "a globalização (na forma de especialização flexível e da estratégia de criação de 'nichos' de mercado), na verdade, explora a diferenciação local". Concretamente, a falta de um diploma de ES pode ser vista como fator que promove o risco social.

As políticas de inclusão funcionam como um potente e eficiente dispositivo biopolítico a serviço da manutenção da segurança das populações. Elas não podem ser entendidas apenas sob o tom de intenções de consumo e profissionalização. Elas também têm em seu horizonte a diminuição da tensão social, logo, o aumento do controle das populações. São políticas que compartilham uma mentalidade de governamento que se destina às parcelas da população consideradas vulneráveis aos riscos sociais de discriminação, marginalização, pobreza e consequente exclusão social.

Dentro do espectro analítico da inclusão, a possibilidade de aprender, de participar da vida pública e da sociedade da informação e do conhecimento, mediante a obtenção de um diploma superior, deve atender a todos, mas não de qualquer jeito. Se a inclusão pode ser vista como uma nova ordem social, incluir, principalmente no ES, configura-se como uma forma de ser e estar no mundo. Nesse novo modo, as velhas estruturas dos direitos sociais, políticos e econômicos, característicos do

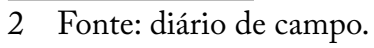


Estado do bem-estar social, transvestem-se para termos-chave das políticas atuais como privatização, descentralização e educação para todos (Ball,2001). Na formação profissional inclusiva são colocados em funcionamento mecanismos que requerem novos sujeitos e novas relações entre eles, as instituições e o Estado.

As IESps se enredam nesses objetivos, constituindo-se como entidades capazes de conduzir a si e aos sujeitos ali envolvidos nessa empreitada, por meio de estratégias que operam o controle da diversidade cultural. Desse modo, atendem a uma racionalidade política que investe na normalização dos envolvidos nessa trama. Nos atuais discursos educacionais, a inclusão é vista como importante movimento de mobilidade social e nacional, sem, no entanto, aprofundar o que isso significa e as suas possíveis consequências, tanto em termos locais como globais.

Nessa contingência, a maioria dos alunos da instituição é representante da primeira geração de sua família a ingressar no ES. Muitos ocupam o privilegiado posto de primeiro a alcançar tal façanha. No curso de licenciatura em EF investigado, há oriundos da Educação de Jovens e Adultos (EJA) e do Movimento dos Trabalhadores Rurais Sem Terra (MST) e que viveram a condição de sem-teto. O tamanho do seu corpo discente quadruplicou em menos de uma década em função das políticas oficiais, como Financiamento Estudantil (FIES), Escola da Família, Bolsa Alfabetização, Jovens Acolhedores; das políticas privadas como o Crédito PRAVALER; ou políticas da própria IESp, como Bolsa Atletas, Bolsa Modelos; ou de mecanismos de captação de alunos com descontos, como a Campanha do Amigo ${ }^{3}$.

No entanto, a condição de presença no ES nem sempre implica em ascensão social. A expansão do ES brasileiro, notadamente realizada pelo setor privado, não significa a possibilidade de superação das condições desiguais para toda uma parcela da população que agora pode acessá-lo. Bauman (2008) nos ajuda a compreender esse fenômeno ao afirmar que à medida que o mercado se tornou o espaço modelador da vida, suas leis determinam as disputas pelo poder e reconfiguram as identidades, logo, os processos de inclusão/exclusão. $O$ sujeito que abandona os estudos, mesmo que temporariamente ${ }^{4}$, vive uma identidade na qual tende a culpar-se, responsabilizando-se pela falha e subjetivando-se no interior dos discursos da oportunidade do mercado. $\mathrm{Na}$ esperança por dias melhores, de um dia para o outro, sua identidade é deslocada. Esse processo pode ser entendido, conforme assinalou Bauman (1999), como uma fábrica de imobilidade, que produz (e avisa sobre) os perigos que a saída precoce do ES representa para o sujeito: privação de bens materiais e degradação social ${ }^{5}$.

3 Fonte: diário de campo.

4 A instituição canaliza esforços para que alunos desistentes façam rematrícula, mesmo após longo período de ausência. Fonte: mensagem eletrônica enviada para a comunidade educativa.

5 Uma aluna relatou que, apesar de não compreender a matéria, não poderia ficar retida naquele semestre. Alegou que para sustentar o custo adicional teria de realizar serviços de faxina. Fonte: diário de campo. 
Nesse jogo de entradas e saídas, a identidade dos sujeitos fragmenta-se mediante ocorrências que não foram previstas.

É possível avaliar a construção da identidade e da diferença no interior desse jogo. Se a identidade está frequentemente diante de processos e efeitos de linguagem que tentam fixá-la, torná-la a norma, os processos de inclusão e exclusão presentes no ES e constituídos por discursos econômicos contribuem para validar os sujeitos que superaram a condição imposta. Essa identidade, o sujeito-cliente, aquele que é capaz de arcar com os custos do serviço educacional e sobreviver diante de outras condições indesejáveis, torna-se o imperativo do processo, a norma. As tecnologias de governamentalidade empregadas agem sobre o corpo dos indivíduos, classificando-os e coisificando-os. É a partir desse modelo normatizado que se estabelece a produção do sujeito-cliente.

A situação descrita contribui para depreciar ainda mais os oriundos de certas camadas sociais ao atribuir-lhes a pecha de incapazes e, concomitantemente, de improdutivos, discurso corrente tanto entre docentes como discentes 6 . O que não se diz é que esse ato é político, decorrente das relações de poder. Em tempos de neoliberalismo e globalização, cabe àquele que não pode pagar pelos seus desejos a benevolência de alguns setores sociais e o descaso do Estado. Em suma, o sujeito-cliente no interior do ES naturaliza a representação de quem se esforça, aproveita a oportunidade que o mercado oferece e, com isso, apaga as condições de sua fabricação. O problema é a tendência à imobilização do processo de significação, aumentando, de um lado, os riscos da imobilidade social para os que ficam de fora dessa onda cultural e, de outro, reforçando o significado da superação para aqueles que não caem nesse percurso. Não é à toa que muitos alunos do centro universitário investigado se encontram em faixa etária avançada ou são retornados ${ }^{7}$.

Para Giroux (2003), a cultura empresarial instaurada na sociedade contemporânea alardeia que a cidadania é uma questão privatizada. Seu objetivo é produzir sujeitos competitivos interessados em si mesmos e no seu ganho material. Ao ingressar no ES e sobreviver na lógica empresarial proposta, o sujeito-cliente tende a desvalorizar as disputas políticas pela democracia e valorizar a lógica do mercado. É nessa situação que as identidades, os valores e as práticas do mercado são produzidos e reproduzidos. Segue o autor afirmando que "a boa vida, de acordo com esse discurso, é construída em termos de nossas identidades como consumidores - somos o que compramos" (p. 53). O sujeito-cliente do ES é aquilo que o status obtido por meio de aportes econômicos lhe possibilita ser. Independentemente de questões de gênero, religião e etnia, o sujeito-cliente é aquilo que pode comprar.

Constata-se, com isso, que as IESps são inclusivas a partir do momento em que garantem o acesso e o atendimento a todos, mesmo que, no decurso dos processos vividos na formação, como, por exemplo, as diversas formas de comparação

6 Fonte: diário de campo.

7 Expressão alusiva à experiência portuguesa de retorno de seus filhos à pátria após anos de ausência em função da diáspora provocada pelas guerras de independência das províncias ultramarinas durante o Governo Salazarista. Utilizamo-lo aqui para marcar o processo de alunos que abandonaram os estudos por motivos diversos e o retomam adiante. 
e classificação que vivem os discentes no transcorrer do curso, fomentem condições de exclusão. A presença de sujeitos de classes desprivilegiadas no interior de uma IESp cria uma ambiguidade, pois no mesmo espaço-tempo os sujeitos podem viver a situação de inclusão e exclusão. Parece que as políticas que promovem a igualdade de acesso não garantem a inclusão e, na mesma medida, não afastam a sombra da exclusão (Veiga-Neto e Lopes, 2007).

Com a participação da federação, de estados e de municípios, do terceiro setor, das entidades privadas, das instituições religiosas ou de esforço próprio, a inclusão dos sujeitos das classes populares tem, ainda que de maneira insuficiente, oportunizado o alcance de novos degraus na escolarização e, para boa parcela, modificado sensivelmente as suas condições de existência. Apesar das dificuldades de muitos em prosseguir nos estudos ou mesmo de acompanhá-los a contento, a instituição, que não é uma entidade filantrópica, disponibiliza mecanismos para a permanência, tais como: possibilidade de cursar disciplinas atrasadas em outros horários, parcelar dívidas financeiras, reingresso em caso de abandono etc.

Trata-se de estratégias de proteção tanto dos seus interesses como os de seus sujeitos-clientes. Afinal, se, de um lado, busca minimizar os índices de abandono, por outro, prorroga expectativas e/ou ilusões de parte dos seus sujeitos. O que pode ser caracterizado como novas modalidades de estímulo e sedução para capturar e manter seu sujeito-cliente alimentadas pelo ideal da livre escolha. Decerto, percebe-se que a instituição apresenta propostas concretas para a superação dos dados de evasão divulgados pelo Ministério da Educação (MEC) por meio de discursos que realçam o mérito, a performatividade ${ }^{8}$ o empenho (Quadro 1).

Tomando o material no Quadro 1 para análise na sua totalidade, entendemos que tanto a oferta variada de preços e horários como as opções de negociação viabilizadas são práticas características da governamentalidade neoliberal. Como tal, são práticas instauradas para a regulação e o governamento das condutas dos indivíduos, e, assim sendo, são produtoras de identidades nas sociedades atuais. O que se tem é um rol de condições que se apresenta como apropriado para que os sujeitos-clientes sejam capazes de fazer suas escolhas mediante sua suposta liberdade. $\mathrm{O}$ efeito sobre a subjetividade é ainda maior, pois o sujeito-cliente toma para si a responsabilidade sobre os possíveis desdobramentos de suas negociações. Ao optar por uma das vias ofertadas, ele terá de gerir seu tempo e suas condutas em acordo com o compromisso que firmou com a instituição e tentar dar conta dele.

O governo de si, nesse caso, também está relacionado aos aspectos produtivos, seja no âmbito do trabalho ou no da escolarização. No trabalho, relaciona-se à produção específica de seu ramo de atividade, pois sem ela não lhe será concedida a chance de obter uma bolsa de estudos e, assim, progredir na vida. Nos estudos, em muitas situações, um dos critérios que firma e mantém os descontos está indexado ao aproveitamento satisfatório dos estudos. Em caso de reprovação, o bolsista poderá

8 Nos termos de Ball (2004), trata-se de uma tecnologia, uma cultura e um modo de regulação, que implica julgamento, comparação e exposição, tomados, respectivamente, como formas de controle, de atrito entre as pessoas e de mudança de atitude. 
perder essa oportunidade ou terá de arcar com os custos. Essa é uma técnica que insere o sujeito na lógica da produtividade.

Tais ofertas apresentam outro viés articulado à análise acima. Elas estão em acordo com as diretrizes propostas pelo Banco Mundial, que vê nas IESps a

\title{
Quadro 1 - 16 caminhos para bolsa de estudo ou alternativas para viabilização de estudos em nível superior.
}

\begin{abstract}
Prezadas Alunas, Professoras e Coordenadoras,
Prezados Alunos, Professores, Coordenadores e

Demais Colaboradores

Confirmamos que a Instituição é obrigada a analisar caso a caso os pedidos de

concessão de bolsas de estudos, por uma questão estratégica de aplicação de

recursos financeiros e, também, para melhoria autossustentável das condições de

oferta de nossos cursos e demais programas acadêmicos e comunitários.

Esclarecemos que o [...] oferece pelo menos 16 caminhos para auxiliar na viabilização dos estudos

de seus alunos, sendo que a priori não trabalhamos com a hipótese de concessão de bolsa integral

ou de $100 \%$, inclusive para garantir a valorização do próprio benefício. Portanto, temos:
\end{abstract}

1- Financiamentos alternativos por meio da orientação da área Financeira do [..] (Ex:

Escola da Família - FIES - Bolsa Universidade - Crédito Prá Valer, entre outros);

2- O aluno pode candidatar-se a uma vaga de estágio no [...], com a concessão de desconto especial

3- $\mathrm{O}$ aluno pode candidatar-se a uma vaga de emprego efetivo no [...], com

a concessão de bolsa integral, conforme convenção trabalhista;

4- Pagar em dia suas mensalidades gera desconto automático de $10 \%$.

5- O aluno ser funcionário de empresa com parceria formal com o [...]; concessão de $10 \%$ de desconto, que se acrescenta ao desconto por pontualidade, resultando em $20 \%$ por mensalidade paga.

6- $\mathrm{O}$ aluno ser atleta de destaque em modalidade esportiva ou de uma equipe patrocinada pelo [...];

7- $\mathrm{O}$ aluno ser Monitor de uma das disciplinas de seu Curso, auxiliando o

professor junto aos seus colegas; há desconto especial nas mensalidades.

8- O aluno ser Representante de Turma; há desconto especial nas mensalidades;

9- Participação da Campanha do Amigo que permite benefícios auspiciosos para os alunos.

10- Descontos especiais de $50 \%$ nos horários das $23 \mathrm{~h} ; 5 \mathrm{~h} 45 ; 7 \mathrm{~h} 20$ ou

$8 \mathrm{~h} 30$ e $13 \mathrm{~h} 30$ ou $14 \mathrm{~h} 20$; verificar cursos, caso a caso;

11- O aluno ser associado de Instituição do terceiro setor com parceria específica com o [...];

12- Há desconto especial para os alunos funcionários públicos municipais

das cidades de (...) e (...); seus parentes diretos e agregados;

13- Participação no projeto Bolsa Alfabetização, para alunos da área de Educação,

garante-se até $100 \%$ de bolsa em função de financiamento público específico.

14- O aluno pode oferecer Oficina, isto é, dar treinamento para outros alunos

a partir de habilidade pessoal atlética, artística ou cultural; essa opção concede

ao aluno remuneração de mais de $80 \%$ do valor arrecadado.

15 - Oferecemos $50 \%$ de desconto para ex-alunos que tenham interesse em cursar uma segunda graduação no [...] de acordo com análise curricular.

16- Concedemos, normalmente, $5 \%$ de desconto, não cumulativo, por parentesco (irmão - irmã - pai e mãe).

Fonte: mensagem eletrônica enviada para a comunidade educativa. 
possibilidade de satisfazer a demanda pelo ensino pós-secundário dos estudantes desprivilegiados economicamente. Do mesmo modo, a preocupação com a manutenção da clientela, manifesta nas mais variadas formas de acordo, indica, no plano jurídico-econômico, a influência da OMC, que, no ano 2000, sinalizou para o capital que um dos espaços mais fecundos para negócios rentáveis era o campo educacional (Stoer, 2002).

No caso das diretrizes do Banco Mundial, elas enfatizam que o ES é um bem privado, e não público, pois, segundo Sguissardi (2006), apresenta características mercantis, como as condições de competitividade (oferta limitada), excluibilidade (pode-se obtê-lo mediante pagamento) e recusa (não é requerido por todos), o que o torna subordinado e consentido à lógica do mercado.

Ao que tudo indica, essas ações favorecem a adaptação dos sujeitos às tendências atuais de reestruturação econômica e política. Nesse bojo, não é de se estranhar a possibilidade de financiamento público para a formação de sujeitos na educação privada. Essa modalidade de oferta torna-se mais emblemática por ser parte de uma agenda divulgada por uma instituição particular. Diante da carência de ações do Estado, a publicização desses "caminhos" reforça a plataforma neoliberal de reestruturação educacional do ES e as parcerias entre o Estado e as empresas como algo necessário. Por aqui, confundem-se interesses políticos diversos e talvez isso contribua para que as identidades constituídas nas IESps borrem as fronteiras entre o público e o privado, naturalizando o encampamento do primeiro pelo segundo.

Nessa naturalização apagam-se as lutas que ocorrem nas fronteiras do campo contestado da cultura. Em seus estudos acerca das transformações na educação da Comunidade Europeia, Ball (2004) denuncia que, diante do novo gerencialismo da educação, os governos locais incentivam as diversas investidas do setor privado na gestão das escolas públicas. Os sistemas locais alegam formar parcerias que possibilitam a melhor gestão dos custos com a educação. No entanto, o que se vê nos discursos das empresas é a possibilidade de aumento dos seus lucros e ganho de um capital certo, pois a organização emprega uma série de artifícios para escapar da concorrência e da inadimplência. A inserção, o domínio e a usurpação do bem público são legitimados por práticas discursivas e não discursivas da ineficiência do Estado que, diga-se de passagem, foram instauradas pelos próprios agentes do interesse privado.

No Brasil, a presença histórica do setor privado no ES e as políticas públicas pós-1990 solidificaram essas questões. Além dos discursos de inoperância do Estado, corroboram a fortificação do Pós-Estado da Previdência as parcerias que o governo instaura no ES com o setor privado, a fim de dar conta de modo emergencial das pressões externas por produção e das internas por demanda de vagas. Isso está evidente nas parcerias firmadas entre a instituição e os órgãos públicos mediante projetos estatais dos quais essa IESp usufrui, como o FIES, o programa Escola da Família e a Bolsa Alfabetização.

Nomeando de Pós-Estado da Previdência, Ball (2004) analisa o processo e as implicações deste para o Estado, para as instituições públicas, para o capital e para os cidadãos. Em particular, seus esforços alertam para a questão da performatividade, com seus hábitos comerciais de produção e utilitarismo no âmbito da escolarização. 
Grosso modo, o autor sugere que a privatização e a mercantilização do setor público fazem parte do processo da globalização e de seus acordos transnacionais, incentivando a competência, o espírito empreendedor e a performance por excelência, minimizando temas como equidade, justiça social e diferença. No ES privado isso não é sugestão. É um pacto social/comercial.

Ao ingressar no ES privado, o sujeito-cliente, muitas vezes vítima de processo de exclusão vivido na escolarização básica, passa a conviver com outros processos de exclusão mais sutis. Se antes a educação como direito lhe fora negada na prática, agora pode lhe ser negada porque se trata de um negócio que envolve uma relação comercial. Mediante os riscos que se corre, a negociação entre o sujeito-cliente e a IESp facilita silenciosa e rapidamente a mercadização da educação. Para os sujeitos-clientes, a educação pertence à esfera mercantil.

É diante das características que operam o sujeito-cliente que frequentemente o centro universitário divulga seus diferenciais como estratégias de marketing e autopromoção em veículos de comunicação externa e interna. Os anúncios se destacam no site, em banners e folders de publicidade, nas mensagens eletrônicas enviadas a toda a comunidade, em reuniões docentes e nas diversas formas de acolhida aos alunos (Quadro 2).

Os diferenciais divulgados fazem parte de estratégias e inúmeros esforços de gerenciamento do cenário em que os sujeitos atuam, a fim de sustentar representações que relacionam qualidade e excelência com oportunidade. Estratégia que coloca lado a lado a instituição e seus sujeitos e que é parte de um processo de aceitação da noção de eficiência. Os diferenciais propiciam a cada sujeito da organização a possibilidade de exprimir sua iniciativa individual e desenvolver seu potencial.

As representações apresentadas não atingem a todos, tampouco fazem com que os sujeitos endereçados se importem uns com os outros. O que se tem são fluxos de desempenho tanto do sujeito como o da organização. O que se apresenta é a construção de produtos institucionais convincentes e o desejo, a partir das oportunidades ofertadas, de ser sujeito competente. Desse modo, contribui-se para que qualidade e excelência se tornem as representações adequadas destes tempos.

A mensagem explicita que as ofertas institucionais valorizam enfaticamente os valores eminentes do mundo do mercado, como autonomia, responsabilidade social, atualização constante, espontaneidade, flexibilidade, criatividade e atitude proativa, tudo em plena sintonia com os ideais da sociedade do conhecimento, e, desse modo, contribuem para a que a linguagem da educação passe a ser a linguagem do trabalho reestruturado do sistema pós-fordista. Mais ainda, eles formam um caldo apetitoso com ingredientes de produção — os diferenciais que permitem ao sujeito o conhecimento e a valorização dos que dele se servem - e ingredientes de consumo - os diferenciais que seduzem a presença dos sujeitos-clientes e sua participação ativa.

Os diferenciais de qualidade e excelência não se enquadram simplesmente na lógica mercantil da diversificação de produtos endereçados aos consumidores receptivos a tudo isso. Eles se transformam em normas, orientando os sujeitos para as mudanças da sociedade global. Os diferenciais se tornam necessários à subjetivação do sujeito-cliente para sua inserção na sociedade regulada pelo mercado. 
Ao divulgar ações que se articulam estritamente com as concepções do mundo econômico, desde a relação entre professor e aluno até os modos como as aulas são efetuadas, o enunciado faz crer que uma instituição atualizada é aquela que cria condições de aprendizagem consoantes com o mercado de trabalho e o sujeito ideal é o que aprende esses atributos. Ao proferir os diferenciais, o centro universitário não está apenas descrevendo um fato, fazendo publicidade, cativando sujeitos-clientes. Está inserindo seus sujeitos em um sistema de significações que reforçam relações de poder presentes em um mundo fortemente influenciado pelos

\section{Quadro 2-Diferenciais.}

1 - Espaço privilegiado no campus para desenvolvimento de atividades acadêmicas, práticas profissionais e sensibilização para responsabilidade socioambiental;

2 - Aulas interativas e não apenas contemplativas;

3 - Comunicação do aluno em "tempo real” com a Direção da Instituição;

4 - Uma escola onde professores e alunos interagem como "sujeitos ativos" no processo de ensino-aprendizagem;

5 - Uma escola onde professores e alunos se fazem uno na ação sinérgica do aprender, apreender e intervir nas comunidades circunvizinhas;

6 - Uma escola que no horário de aula tem aula, com qualidade;

7 - Nossos professores são mestres e doutores com notória competência acadêmico-profissional, inclusive, nas pesquisas institucionais são considerados, pelos alunos, como um dos pontos mais fortes da instituição;

8 - Cursos livres, em formato de oficinas, ministrados pelos próprios alunos, explorando habilidades pessoais ou experiência profissional de mercado; os alunos são remunerados para tal fim, estimulando-se o empreendedorismo ou a primeira ação acadêmico-profissional;

9 - Programa de monitorias que propicia aos alunos a oportunidade de desenvolver habilidades para uma carreira acadêmica na docência, com benefício de bolsa de estudos;

10- Grupo de Excelência e Desenvolvimento Intelectual, no qual os melhores alunos, de todos os cursos e séries, têm reuniões periódicas, sob a tutela de professora orientadora, onde discutem conhecimentos e criam novos conhecimentos; serve de instrumento para iniciação científica, inclusive para publicação de trabalhos;

11 - Os projetos pedagógicos dos cursos levam em conta os paradigmas contemporâneos, afora a sustentação científica, sendo flexíveis para adequação segundo o cenário do respectivo perfil profissiográfico de cada segmento do mercado profissional;

12 - Semana de palestras, seminários e workshops com a presença de profissionais respeitados e reconhecidos no mercado, trazendo situações atuais de mercado e de vivência profissional, com a oportunidade de interagir e questionar sobre temas afins ao segmento escolhido pelo aluno;

13 - Atlética, laboratórios, clínica de fisioterapia, ginásio poliesportivo, piscina semiolímpica e teatro que possibilitam aulas práticas ou a simulação de ambientes profissionais durante a integralização dos conteúdos dos cursos;

14 - Promove anualmente a entrega de um prêmio com ênfase no desenvolvimento profissional para reconhecimento público de alunos com melhor performance acadêmica e representantes da sociedade com notória competência profissional em suas áreas de atuação;

Fonte: mensagem eletrônica enviada à comunidade. 
discursos da cultura empresarial e que invadem a educação. É sua repetição constante que fortalece um ato linguístico e a produção da identidade do sujeito-cliente.

Ao anunciar as ações institucionais como diferenciais, não se está meramente manifestando uma opinião. Está-se a retirar as expressões de um contexto mais amplo em que esses significados foram enunciados diversas vezes e inserindo-os em um novo âmbito sob o disfarce da novidade. É essa citação que recoloca o enunciado performativo em ação, reforça e produz as representações do mundo do mercado como próprias do ES. Reforça a educação como produto e o sujeito como consumidor. Os diferenciais funcionam como agentes da normatização do modo de ser empresarial no ES.

Enquanto produto a ser ofertado, seja na forma de bens, seja como serviços, os diferenciais criam a sensação de estarem perfeitamente ajustados para atender a uma demanda que é particular para aquele grupo de sujeitos - os estudantes e de serem naturais no processo formativo. Ou seja, eles atuam de modo que o sujeito-cliente, diante de sensação de liberdade, possa fazer a escolha adequada para os seus investimentos pessoais, reduzindo a educação a uma commodity.

A partir do momento em que a educação passa a ser uma commodity, fica difícil pensar na existência de alguma barreira entre qualquer política pública e diferentes setores da atividade econômica. Essa propensão confirma a posição de Stoer (2002), para quem a mudança da economia capitalista mundial requer um novo modelo de educação, no qual o imperativo econômico assume o papel principal no processo de globalização da educação em detrimento das dimensões cultural e normativa que caracterizavam a escola há algum tempo. Isso implica mudanças nas relações entre os sujeitos, nas práticas cotidianas que os envolvem e na administração e organização das instituições de ensino, em suma, do currículo. Só assim a globalização poderá estabelecer efeitos, ainda que intensamente mediados pelo local, sobre os sistemas educativos, logo, sobre a população. A comodificação da educação torna-se um processo de ressignificação num ambiente permeado por outras formas de relação entre as pessoas. Uma relação estabelecida pelos padrões da negociação, semelhantes ao jogo em que se dão as relações entre consumidores e seus objetos de consumo.

Como commodity, a educação não pode dar prejuízo. No caso específico investigado, ela se insere na esfera privada, logo, está voltada para o lucro, envolvendo a produção de bens e serviços para o mercado e inserida na lógica da concorrência. Nessa inserção, os problemas de gestão, como inadimplência, desistência, novas matrículas e transferências, somente podem ser resolvidos mediante a percepção dos problemas específicos de sua população-alvo de forma calculada e sistematizada. Daí a elaboração de estratégias que atendam às necessidades institucionais e de seus sujeitos-clientes.

Essa perspectiva implica a transformação/inserção da educação na lógica da oferta e da procura. De um lado estão os que oferecem os serviços educacionais e, do outro, os que escolhem e consomem. Aos primeiros, caberia criar as condições de permanência. Estas não são apenas econômicas, pois a concorrência também apresenta as suas estratégias de conquista de sujeitos-clientes. Elas devem estar atreladas às questões de afeto e desejo. Não à toa, a IESp sede da investigação e tantas outras investem capital nas condições do ambiente em seu interior, na sua 
marca e em outros elementos persuasivos, como, por exemplo, as parcerias com empresas para obtenção de estágios, o corpo docente reconhecido, os horários alternativos, entre outros.

Aos segundos, caberia a análise de aspectos sociográficos que incorrem na relação custo-benefício. A escolha e o consumo do produto dependem de interesses que podem incluir a distância de casa ou trabalho, os custos com material didático, as exigências do curso, o reconhecimento da instituição formadora, as oportunidades de inserção no mercado de trabalho, entre outros ${ }^{9}$. Como expressa Foucault (2008, p. 307): "A economia já não é, portanto, a análise da lógica de processos históricos, é a análise da racionalidade interna, da programação estratégica da atividade dos indivíduos".

O que se está a argumentar é que o ES privado desenvolve uma estrutura na qual as micropolíticas e as microrrelações que ocorrem em seu interior funcionam como representação local das consequências sociopolíticas e econômicas de um mercado global que tenta se espraiar por todos os setores sociais. O ES inserido na cultura do sonho e do consumo se enquadra na lógica neoliberal. Essa cultura que opera a produção de identidades e constitui o sujeito-cliente fornece e recria outras paisagens e, por conseguinte, outras formas de subjetivação.

\section{O SUJEITO-CLIENTE E AS PARTICULARIDADES DA EDUCAÇÃO FÍSICA}

Mediante as formas de subjetivação presentes no interior do currículo de licenciatura em EF analisado, cabe o comentário corrente entre alguns professores do curso referentes à grade curricular. Na visão deles, o curso deve privilegiar um rol significativo de disciplinas que denominam práticas (natação, basquete, ginástica etc.) nos dois primeiros semestres, a fim de cativar os ingressantes, pois, caso a ênfase nesse período recaia em disciplinas tidas como difíceis, com muita leitura, $\mathrm{o}$ aluno poderá abandonar o curso ${ }^{10}$. Posições curriculares que, por um lado, fixam um estatuto de verdade para o currículo da formação em EF como área do saber prático e este como menor valor diante dos saberes intelectuais, o que confirma a hierarquização de saberes que ocorre na área (Neira e Nunes, 2009). Do outro, essas posições estão pautadas na relação com o possível interesse do cliente, e um cliente bem específico - o praticante de atividade física e/ou aquele que não gosta de estudar.

Se as relações entre as mudanças globais, as políticas públicas locais, a cultura institucional e o sujeito-cliente buscam fixar a lógica do mercado à educação, não é por acaso que prolifera toda a gama de cursos de especialização, sobrecarregando as caixas de mensagens eletrônicas dos discentes. Há ainda os eventos que compõem as semanas de eventos ${ }^{11}$, mediante as quais seus sujeitos são interpelados pelos

9 Explicações de alunos para a escolha da faculdade. Fonte: diário de campo.

10 Fonte: diário de campo.

$11 \mathrm{Na}$ IESp que acolheu a investigação ocorrem além da Semana de Educação Física, as Semanas da: Educação; Enfermagem; Meio Ambiente e Negócios, entre outros momentos em que se misturam produções dos alunos com palestras de diversas finalidades e venda de produtos afins. Fonte: e-mails institucionais, material publicitário e portal da internet. 
produtos do mercado. Além desses, com frequência, as aulas são interrompidas sem aviso ou programação anterior para que os alunos assistam a palestras que exaltam o empreendedorismo, cuja exigência de presença obrigatória sofre questionamentos de docentes e discentes em relação aos possíveis interesses mercantis e pessoais em jogo.

Em certa ocasião, a semana de atividades que substituiu as aulas regulares não dispunha de nada que interessasse à licenciatura. Palestras e oficinas direcionavam-se ao campo do bacharelado e em sintonia com o mercado de atuação do profissional da EF. Os temas abarcavam o mercado de fitness (bases profissionais e mercado de trabalho); perfil do profissional de EF no século XXI (centrada no mercado de trabalho); treinamento funcional; ginástica rítmica desportiva; a carreira de atleta de futebol; e, por fim, apresentações de dança. Fugindo à regra, em um final de semana foi organizado um Seminário de Educação Física Escolar, porém sem participação dos estudantes. Além de ser fora do horário de aulas, o evento promovido por uma empresa do setor era pago, sem descontos para os alunos locais e dirigido a um público variado. A instituição apenas cedeu suas instalações para a realização do evento cuja maioria dos presentes atuava no sistema de ensino privado. Fato que ilustra o convívio na educação de empresas que se beneficiam e constituem a mercadização dos saberes acadêmicos.

Ainda com enfoque no mercado de trabalho, foram identificados nos murais do curso de EF 22 cartazes de divulgação de eventos, tais como: Fitness Brasil Internacional; Taça Metropolitana de Ginástica de Trampolim (com oficinas gratuitas); Encontro Nacional de Atividade Física (ENAF); e os mais variados cursos de especialização promovidos por IESp com chancela do sistema Conselho Regional de Educação Física/Conselho Nacional de Educação Física (CREF/ CONFEF). As palestras sobre rúgbi e remo, por exemplo, apesar de abordarem aspectos formativos, enfatizaram o grande potencial de oportunidade de trabalho para os estudantes, tendo em vista a proximidade dos Jogos Olímpicos no Rio de Janeiro e a escassez de mão de obra para esses setores. O sistema de ginástica Body System também marcou presença com atividades de divulgação da franquia criadora do programa e recrutamento de estagiários.

Baseada na relação de interesses entre a formação acadêmica e o sujeito- cliente, a realização dessas atividades deu-se em horário de aula, mas contabilizando horas de Atividades Acadêmicas, Científicas e Culturais (AACC). Como todo o processo sofre a recontextualização, no curso investigado, as AACC não escapam do enredo mais amplo. Apesar da obrigação legal quanto ao cumprimento dessa carga horária realizar-se para além do período, no curso em foco, isso nem sempre acontece, descaracterizando a sua determinação oficial. $\mathrm{O}$ fato deve-se à desconfiança de que os alunos não iriam aos eventos se não houvesse formas de controle, como lista de presença e entrega de um breve relatório. Esses dados denotam a visão corrente a respeito dos eventos e dos alunos.

Enquanto sujeitos-clientes, os estudantes elaboram estratégias de negociação. Aqueles que já completaram a carga de horas complementares exigida dizem aproveitar o momento para realizar outras atividades, acadêmicas ou não. Muitos questionam o docente se a palestra realmente vale a pena. Alguns reclamam a perda da aula do dia e pedem reposição, enquanto outros consideram interessante 
a variação de assuntos. Sem falar naqueles que apreciam o cancelamento de uma parte da aula. Em geral, esses momentos são realizados com audiência bem abaixo do total de alunos do período ${ }^{12}$.

Os fatos narrados indicam que a relação entre as mudanças globais, as políticas públicas locais e a cultura institucional acaba por fazer com que os sujeitos e a própria IESp sejam governados com base na relação custo-benefício, tanto econômico como simbólico. Entendemos que a relação estabelecida a partir das trocas anunciadas pode condicionar a participação de qualquer grupo social no interior da IESp ao pensamento restrito da educação como um serviço a ser escolhido para o consumo. Não à toa, esta e outras IESp fazem propagandas com base nos resultados oficiais do Índice Geral de Cursos (IGC). O que se objetiva com a encampação do ES pela cultura empresarial é a formação de identidades normalizadas e performáticas (Giroux, 2003).

Entendemos essas tentativas de fixação de identidades como um dos aspectos centrais do jogo do poder contemporâneo em que se acentuam novas formas de interdição dos discursos. Foucault (2006) sublinha que a interdição dos discursos revela sua ligação com o desejo e o poder, ao escancarar aquilo que se quer apoderar. A educação comodificada, com seus discursos de oferta e procura, é um acontecimento que faz com que o campo de sua análise se estenda para a esfera econômica e a transforme na vontade de verdade que determina o presente, profetiza o futuro dos interessados, da nação e da globalização. A comodificação da educação é uma potente prática de significação destes tempos em que a luta por equidade, reconhecimento e democracia esbarra na luta por nichos de mercado, interesses individuais e rendimentos.

A educação como mercadoria e as negociações dela decorrentes fazem a nova ordem instaurada no ES privado funcionar como articulação entre o poder disciplinar e o biopoder. Como explica Foucault (2005), enquanto técnica, o biopoder não exclui a técnica disciplinar, mas a integra, a modifica parcialmente, atuando em outra escala, auxiliada por instrumentos diferentes.

Os problemas políticos e econômicos presentes no ES fazem aparecer uma tecnologia de poder que se aplica à vida dos estudantes. Ou seja, o funcionamento da disciplina e o funcionamento do biopoder passam pela problemática da definição daquilo que pode ser classificado como de ordem pública e daquilo que pode ser nomeado como de ordem privada. A educação é um caso explícito que condensa essa questão. Nela, é preciso disciplinar os corpos individuais para compor uma população. Ao mesmo tempo, esses corpos têm de ser massificados para serem disciplinados com mais eficiência, o que significa alcançar menor gasto com os sujeitos, a fim de se obter deles maior produtividade, que é, para Foucault (2008), a máxima da arte de governo neoliberal.

É essa articulação que permite que os sujeitos-clientes sejam disciplinados em sua produtividade individual (privada) e localizada (no ambiente do trabalho e/ou no de estudo), e, ao mesmo tempo, possibilita o seu encaixe nas curvas esta-

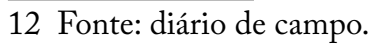


tísticas do ES, massificando-os, classificando-os e regulando-os. É essa articulação que permite a produção e circulação de discursos que enfatizam a valorização do sistema privado em detrimento do sistema público. Pode-se considerar que as ofertas e as negociações entre as partes interessadas funcionam como uma das formas de regulação da cultura das IESp e de seus sujeitos, contribuindo para determinados direcionamentos comuns.

A naturalização dos discursos performáticos e da comodificação da educação se solidifica em tempos nos quais o controle da população se volta para a produtividade e para o consumismo, afastando, também, os estudantes do debate público. Não é mero acaso que no curso de licenciatura em EF investigado sejam dominantes os discursos da saúde e da atividade esportiva ${ }^{13}$. Ambos operam como estratégias biopolíticas tanto neo-higienistas, que visam a garantir a ação de sujeitos saudáveis, quanto eficienticistas, com vistas à aprendizagem de modos de ensinar técnicas de movimento, valorizando o sujeito competente. Estão articuladas com a produtividade e fortalecem o consumo no mercado das práticas corporais, pois centram esforços em uma formação voltada para os setores em que as práticas são mercadizadas. Não deixa de ser interessante observar que no juramento proferido durante a cerimônia de formatura o sujeito promete alinhar-se a essa ordem (Quadro 3).

São perceptíveis os ecos dos ideais promovidos pelo sistema CONFEF/ $\mathrm{CREF}^{14}$, que, como se sabe, comunga com o projeto social neoliberal. Observa-se que o licenciado irá atender aos princípios éticos do profissional da EF. Princípios elaborados por sujeitos partidários do ideário de um profissional pragmático e mercantil. Um mero prestador de serviços que só existe porque há um cliente, tornando necessário o estabelecimento de uma relação. Ser sujeito-cliente implica em saber se relacionar com outro sujeito-cliente. A identidade do docente de EF que se projeta formar parece ficar cada vez mais distante do projeto pedagógico da escola. Afinal, como prestador de serviço para a busca de uma vida ativa e saudável, basta ao egresso promover atividades físicas em espaços que não incomodem os

\section{Quadro 3 - Juramento de educação física - licenciatura.}

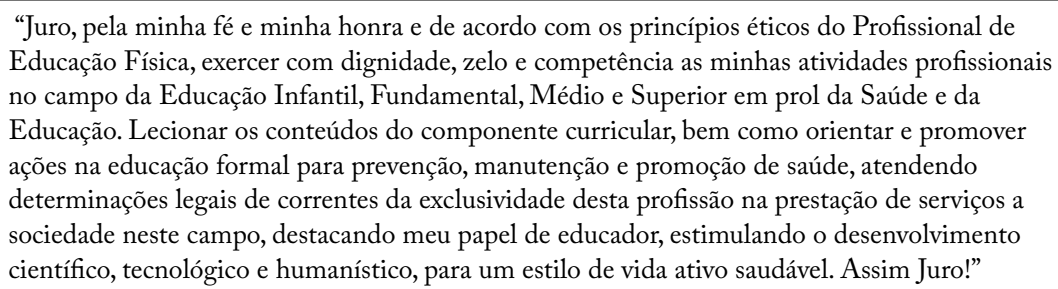

Fonte: texto do cerimonial de formatura dos cursos.

13 No curso de licenciatura investigado $58 \%$ da carga horária são de aspectos biológicos e técnico-esportivos e apenas $10 \%$ da carga total do curso (2.944 h) abordam questões específicas de licenciatura. Fonte: matriz curricular.

14 Trata-se do sistema que regula a atuação do profissional da Educação Física em áreas não escolares. Nos últimos anos, adentrou na área da Educação por meio de normativas que obrigam os professores em atuação nas escolas a se filiarem, ampliando seu espectro de ação. 
demais componentes curriculares, podendo acontecer até mesmo fora da escola e do debate político-pedagógico.

Ao longo dos anos 1980, diversas pesquisas diagnosticaram que a $\mathrm{EF}$ fora historicamente usada no Brasil para reforçar representações dominantes de identidade nacional, gênero, classe social e raça, além de repressão de movimentos estudantis. A continuidade dessas representações no currículo de formação inicial foi denunciada por alguns estudos recentes (Sá Oliveira, 2006). Sem abandonar o esporte como base, essa condição parece recrudescer e ter ganho nova roupagem com o discurso presente da qualidade de vida, da inclusão e do consumo das práticas corporais.

Para Bracht e Almeida (2006), a expansão do ideário neoliberal e o consequente arrefecimento das instituições públicas diante das imposições do mercado causam impacto no âmbito da EF e da cultura corporal ao promover a permuta da noção de que o acesso às práticas corporais é um direito do cidadão pela noção de que seja um direito do consumidor. Dialogando com Bauman, os autores reforçam que nessas práticas e nesse direito o indivíduo transforma-se de cidadão político em consumidor de mercado. O resultado é o aumento do abismo entre sua heteronomia e a sua autonomia plena, tendo como resultado a pseudoliberdade de escolha.

A essas questões, outro aspecto merece ser adicionado. É importante o alerta sobre os efeitos do tipo de representação de corpo presente na formação inicial de $\mathrm{EF}$ e a relação desta com o sujeito-cliente. O corpo esportivo é eficiente, saudável, máquina. Esse corpo é destituído de emoções, cultura, experiências. Esse modelo de corpo ganha mais espaço nas aulas em que se aprende sobre o corpo biológico. Em algumas são utilizados cadáveres ou ossos plásticos. Em outras, o corpo é apresentado por meio de imagens unidimensionais, fotos de órgãos, células e modelos de reações químicas. Esse é o corpo produzido pela linguagem do Iluminismo, um corpo universal e abstrato. Um corpo que não é de ninguém, não tem raça, credo, classe social, idade, gênero etc. Um corpo isolado das experiências sociais e sensoriais, que cada sujeito experimenta em si mesmo no cotidiano. Uma vez isolado dos aspectos afetivos e culturais que o constituem, o corpo máquina torna-se suscetível à manipulação dos cientistas (Macedo, 2005). Sendo um artefato moldável, as formas de intervenção sobre o corpo também se tornam negociáveis, potencializando a formação mercantil dos estudantes.

Do mesmo modo, outros campos teóricos presentes no currículo, como as disciplinas de psicologia, aprendizagem motora e desenvolvimento motor, que ancoram a maioria dos trabalhos de conclusão de curso na licenciatura ${ }^{15}$, apresentam as percepções corporais desnaturalizadas e desterritorializadas. O esquema corporal surge como concepção unívoca de corpo, tornando-o aparentemente neutro e os estádios do desenvolvimento parecem ser naturais. Nesse sentido, outros efeitos incidem sobre a formação das identidades dos estudantes. Faz crer que só existe um tipo de relação das pessoas com seus corpos, e que todos alcançarão patamares definidos como universais. Propaga-se que apenas uma cultura, uma visão de mun-

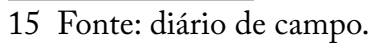


do é a certa. $\mathrm{O}$ resto é desvio, é erro. $\mathrm{O}$ corpo competente é aquele que alcança o que se projeta. Consequentemente, outros efeitos sobre as identidades podem ser correlatos. O corpo apresentado apenas em sua dimensão biológica, por exemplo, faz da sexualidade algo instintivo e vivido do mesmo modo por todas as pessoas. O mesmo pode ser dito quanto à noção de identidade de classe social.

Essa naturalização, sem dúvida, facilita a fixação da linguagem performática, característica da constituição do sujeito-cliente. Os processos de fixação presentes no currículo tornam a aprendizagem dessa linguagem produtora de significados sobre o modo como os futuros professores (e os que ministram as aulas para eles) tratarão tanto seus corpos como os de outros sujeitos, significando-os, talvez, como corpo-cliente e corpo-mercadoria. Não à toa, nos espaços em que as práticas corporais passaram a ser ensinadas mediante situação de compra e venda de serviços, como academias, cursos de danças, escolinhas de esportes etc., são esses os aportes teóricos que sustentam suas pedagogias.

De concreto, pode-se dizer que a formação de um sujeito na mesma matriz teórica (licenciatura/bacharelado) faz da intervenção do professor de EF (dentro e/ ou fora da escola) vital para que certo regime de verdade sobre as práticas corporais se instale ou se mantenha em múltiplos espaços. Quanto à escola, na medida em que nela circular uma concepção de EF que se identifica com a visão dominante de corpo - saudável e eficiente -, caracterizar-se-á como lócus privilegiado para o contínuo processo de produção de consumidores em busca de serviços ligados à promoção da qualidade de vida, logo, da saúde. Serviços esses, cada vez mais, oferecidos e organizados pelas expectativas do mercado.

\section{CONSIDERAÇÕES}

As expectativas do mercado quanto à formação do sujeito-cliente fomentam a relação entre o sistema de ensino e os órgãos supranacionais que determinam as políticas públicas para a educação implantadas pelo Estado. O objetivo é formar o sujeito como um self e como membro de uma comunidade global. Essa premissa torna-se maior à medida que os membros de cada nova geração atuam em sistemas nos quais o pedagógico é governado por um Estado que controla, regula, coordena, comanda, financia e certifica o processo de ensino e aprendizagem sob a égide de interesses globais, principalmente quando concede essa ação para o setor privado. Não é de surpreender que um dos principais propósitos de um sistema educacional projetado dessa forma seja criar um cidadão leal e competente (Burbules e Torres, 2004).

As estratégias aqui descritas, ao funcionarem como tecnologias sociais do currículo da formação inicial, subjetivam os sujeitos-clientes no interior das IESps e passam a normalizar parte da conduta social em um processo de retroalimentação do ES privado, e isso interfere em qualquer currículo disciplinar. $\mathrm{O}$ sujeito-cliente é, sem dúvida, o objeto e o objetivo do ES privado.

É importante ressaltar que a formação do sujeito-cliente é multiforme. Ou seja, ela acontece em vários espaços e de diversas maneiras. Enquanto projeto das políticas globais para a educação, a identidade do sujeito-cliente sofre inter- 
corrências diferenciadas nas IESps diante de características e particularidades institucionais locais. Do mesmo modo, isso acontece no interior dos currículos de seus cursos, seja os da EF ou quaisquer outros. Em se tratando da EF, além da hegemonia epistemológica a que está submetida, o sujeito-cliente é interpelado a atuar de modo diferente em função das estratégias empregadas para a sua captura.

O que se pode perceber é que o sujeito-cliente é um efeito da linguagem que domina a cultura empresarial. Ele é nada mais do que aquilo que se diz dele e das condições em que ele é inscrito. Na perspectiva pós-estruturalista dos estudos culturais, o sujeito-cliente, como mera representação, é pura exterioridade, sem origem, um artefato da história. Ele é um traço material que presentifica um significado instituído em meio às práticas colocadas em circulação pelos processos de significação acontecidos no interior da instituição investigada. $\mathrm{O}$ sujeito-cliente expõe toda a artificialidade que constitui os seres humanos e o ES privado. Como ser artificial, o sujeito-cliente incomoda por mostrar que o processo de formação da subjetividade não é dado para sempre. Ele é muito mais complicado do que imaginamos.

\section{REFERÊNCIAS}

BALl, S. Diretrizes políticas globais e relações políticas locais em educação. Currículo Sem Fronteiras, v. 1, n. 2, p. 99-116, jul./dez. 2001.

Performatividade, privatização e o pós-Estado do bem-estar. Dossiê: "Globalização e Educação: precarização do trabalho docente - II". Educação e Sociedade, v. 25, n. 89, p. 1105-1126, set/dez. 2004.

Bauman, Z. Globalização: as consequências humanas. Rio de Janeiro: Jorge Zahar Editora, 1999.

. Vida para consumo: a transformação das pessoas em mercadorias. Rio de janeiro: Jorge Zahar Editora, 2008.

Barreto, R. G.; Leher, R. Do discurso e das condicionalidades do Banco Mundial, a educação superior "emerge" terciária. Revista Brasileira de Educação, v. 13, n. 39, p. 423-436, set/dez. 2008.

Bracht, V.; Almeida, F. Q. Emancipação e diferença na educação: uma leitura com Bauman. Campinas: Autores Associados, 2006.

Burbules, N. C.; Torres, C. A. Globalização e Educação: uma introdução. In:

Globalização e educação. Porto Alegre: Artes Médicas, 2004. p. 11-26.

Foucault, M. Em defesa da Sociedade. São Paulo: Martins Fontes, 2005.

. A ordem do discurso. São Paulo: Loyola, 2006.

. O nascimento da biopolítica. São Paulo: Martins Fontes, 2008.

Frow, J.; Morris, M. Estudos Culturais. In: Denzin, N. K.; Lincoln, Y. S. O planejamento da pesquisa qualitativa: teorias e abordagens. Porto Alegre: Artmed, 2006. p. 315-346.

Giroux, H. Atos impuros. Porto Alegre: Artmed, 2003. 
Hall, S. A centralidade da cultura: notas sobre as revoluções de nosso tempo. Educação e Realidade, Porto Alegre, v. 22, n. 2, p. 15-46, 1997.

. Da diáspora: identidades e mediações culturais. Belo Horizonte: Editora UFMG, Brasília: Representações da Unesco no Brasil, 2003.

Larrosa, J. Tecnologias do eu. In: Silva, T.T. O sujeito da educação: estudos foucaultianos. Petrópolis: Vozes, 1994. p. 35-86.

Lopes, A. C.; Macedo, E. Teorias de currículo. São Paulo: Cortez, 2011.

Macedo, E. Esse corpo das ciências é meu? In: Amorim, A. C. R. et al (Orgs.). Ensino de Biologia: conhecimentos e valores em disputa. Niterói: Eduff, 2005. p. 131-140.

Neira, M. G.; Nunes, M. L. F. Educação física, currículo e cultura. Phorte: São Paulo, 2009. Popkewitz, T. S. História do currículo: regulação social e poder. In: Silva, T. T. O sujeito da educação: estudos foucaultianos. Petrópolis: Vozes, 1994. p. 173-210.

Sá Oliveira, A. C. P. Representações dos estudantes homens de educação física sobre o ensino das danças folclóricas. 2006. 126f. Dissertação (Mestrado em Educação Física) Universidade Gama Filho, Rio de Janeiro, 2006.

Sguissardi, V. Reforma Universitária no Brasil - 1995-2006: precária trajetória e incerto futuro. Educação E̋ Sociedade, Campinas, v. 27, n. 96 - Especial, p. 10211056, out. 2006.

Stoer, S. R. Educação e globalização: entre regulação e emancipação. Revista Crítica de Ciências Sociais, 63, p. 33-45, out. 2002.

VeigA-Neto, A. Educação e governamentalidade neoliberal: novos dispositivos, novas subjetividades. In: Portocarrero, V.; Castelo Branco, G. (Orgs.). Retratos de Foucault. Rio de Janeiro: Nau, 2000. p. 179-217.

; Lopes, M. C. Inclusão e governamentalidade. Educação e Sociedade, Campinas, v. 28, n. 100 - Especial, p. 947-963, out. 2007.

\section{SOBRE OS AUTORES}

Mário Luiz Ferrari Nunes é doutor em educação pela Universidade de São Paulo (USP). Professor da Universidade Estadual de Campinas (Unicamp).

E-mail: mario.nunes@fef.unicamp.br

Marcos Garcia Neira é doutor em educação pela Universidade de São Paulo (USP). Professor da mesma instituição.

E-mail: mgneira@usp.br

Recebido em 8 de setembro de 2016

Aprovado em 23 de março de 2017

(c) 2018 Associação Nacional de Pós-Graduação e Pesquisa em Educação - ANPEd Este é um artigo de acesso aberto distribuído nos termos de licença Creative Commons. 